\title{
A Visual Depiction of an Educational Robotics Framework Aimed to Foster the Development of Collaboration Skills
}

\author{
Emmanouil A. Demetroulis, Nikos Platis, Manolis Wallace, Angeliki Antoniou, and Vassilis \\ Poulopoulos
}

\begin{abstract}
There is a constantly growing research interest for Educational Robotics and its effects to the development of student skills. Many researchers conclude and state that E.R develops and increases the collaboration skills of students, without presenting a specific strategy or a methodology that supports the whole process. In addition, the reports are not supported by measurable results or observations of elements that comprise the collaboration skills. This research focuses at the creation of the appropriate conditions, strategy and methodology in order for collaboration skills to find solid foundations for development. It is important to be stated that collaboration is not seen as the means to produce learning outcomes, but collaboration and collaboration skills are perceived to be the outcome of this approach. The aim of this article is to provide a visual depiction of our proposed approach.
\end{abstract}

Index Terms-Collaboration skills, Educational robotics.

\section{INTRODUCTION}

In recent years there is a growing interest from researchers in developing the so called " $21^{\text {st }}$ century skills". One very important element that is characterized essential within the skill-set framework of $21^{\text {st }}$ century skills is the ability to collaborate. Teachers and educators are encouraged to introduce new techniques and methodologies within the classrooms in the effort to develop collaboration skills.

Most of research tackles collaboration skills, in educational robotics, as a useful bi-product of group activities. This research views collaboration and collaboration skills as the final outcome of the whole didactic process. Even if collaboration is seen as the final outcome of this research, it should be pointed that collaborative learning may also be present in the process.

Before presenting the structure of this work, it is useful to mention that the first author introduced educational robotics as a computer science teacher for the past 6 years within and outside the classroom environment and participated in three national educational robotics competitions. Even though the results in the competitions were positive and successful, there was a constant concern on the way ER is implemented in terms of techniques and pedagogies. The last 5 months within the pilot phase of implementing a different philosophy approaching ER the results are encouraging in terms of students' behavior in a deeper level.

Published on December 19, 2020

E. A. Demetroulis, N. Platis, M. Wallace, A. Antoniou, V. Poulopoulos

Knowledge and Uncertainty Research Laboratory

Department of Informatics and Telecommunications
But what is this work about? Behind this work there are some fundamental questions. Can ER combined with the appropriate pedagogy help the students develop their collaboration skills? What is considered to be collaboration? What are the collaboration skills that are important to be fostered? How can we foster these skills?

In order to attempt to answer these quite complicated questions there is a need for a clear and precise definition of the terms that are included within the questions. The two main terms that need to be defined initially are the terms of collaboration and educational robotics.

The first section that follows aims to deliver a brief but solid definition as to what the authors mean with the term collaboration. The second section focuses in presenting the educational robotic tool that has been used during this exploratory research attempt. At the next section there is a presentation and analysis of the collaboration skills that comprise the full spectrum of collaboration according to Hesse et al. [1]. The final sections aim to present and analyze the empirical study, the strategies and pedagogies used behind it and the final outcomes of this approach.

\section{Collaboration and Educational Robotics}

\section{A. Collaboration}

Many researchers and scholars argue about the definition of collaboration. In addition there are many scholars that use the terms cooperation and collaboration interchangeably without distinguishing the meanings of the terms. This work approaches collaboration as what Rochelle [2] stated "....as an exercise of in convergence of construction of shared meanings..." Again, Rochelle and Teasley [3] define collaboration as "coordinated, synchronous activity that is the result of a continued attempt to construct and maintain a shared conception of a problem".

In the extensive work of Panitz [4] "Bruffee identifies two types of knowledge as a basis for choosing an approach. Foundational knowledge is the basic knowledge represented by socially justified beliefs we all agree on." This is a very important distinction as to what approach and how to determine the right recipe to follow for the development of collaborations skills. By foundational knowledge Panitz [4] means, "correct spelling, grammar, mathematics procedures, history facts, a knowledge of the contents of the constitution

University of the Peloponnese, Greece

e-mails: (e.dimitroulis,nplatis,wallace,angelant,vacilos)@uop.gr 
etc." Panitz points that Bruffee's work [4] suggests that foundational knowledge is best to be approached through cooperation.

Collaboration on the other hand has a more student centric approach and there is generally more student involvement in deciding the how's and why's of certain tasks. This type of approach gives the space needed to students to start developing conversations and arguments as how to tackle specific problems, negotiate specific strategies and generally decide what path to take. Again, Panitz [4] through the works of Brufee defines "non-foundational knowledge as that which is derived through reasoning and questioning versus rote memory". At this point it is also very important to add another marker of true collaboration. According to Dillenbourg [5] a marker of true collaboration is the quality of interactions, especially the degree of interactivity and negotiability. These two elements are included within the framework that Hesse et al. [1] proposed for the measurement of collaboration quality.

For developing collaboration skills in primary school students, both approaches have to be considered. It is important to have in mind the important distinction between non-foundational and foundational knowledge. If the main focus is to develop collaboration - social skills than the approach has to incline more or totally to the collaborative approach. If the goal is to teach and develop what is commonly referred to as foundational knowledge then the approach has to incline more on the cooperative approach or even a traditional teaching practice.

\section{B. Why Educational Robotics?}

There is an increased interest the last two decades on the effects that educational robotics have in students' learning of subjects such as mathematics, physics, engineering etc. Taking a closer look, it is noticed that E.R is present in competitions, in summer camps and in afternoon off-school classes. Many cases praise the effects E.R has on students' collaboration skills, however, this is not presented by strictly measurable elements. Sometimes, there is also a lack of methodical observation, but just a mere sense that is difficult to be standardized and explained for assessable and teachable settings. This research aims to bridge collaboration theory and educational robotics and produce a set of collaborative skills, together with a didactical methodology that supports their development.

The question, however still remains unanswered. Why is E.R. the right tool for developing collaboration skills? Educational Robotics has emerged as a unique learning tool that can offer hands-on, fun activities in an attractive learning environment feeding students interest and curiosity [6]. It is not very difficult to understand that E.R delivers a playful and joyful feeling to most if not to all students at the primary school age. If educators and teachers in general can have a useful and simply applicable strategy E.R can transform and enhance the students' skills in many levels. But do all students have the opportunity to come in contact with E.R? As mentioned earlier, there many competitions, afternoon workshops and summer camps that offer this initial contact. The issue behind these off - school activities is that some students have the possibility to enroll and follow these activities, what about the rest of students that do not have the possibility to come into contact with such a useful educational tool?
We believe that all students should have the opportunity to be involved with E.R. According to Alimisis D. [7] “...the role of ER should be seen as a tool to foster essential life skills (cognitive and personal development, team-working) through which people can develop their potential to use their imagination, to express themselves and make original and valued choices in their lives. Robotics benefits are relevant for all children; the target group in robotics projects and courses should include the whole class and not only the talented in science and technology children." Even-though there is a relative difficulty in introducing E.R in formal school settings, it offers a great and flexible tool that has to be pedagogically explored in order to become useful.

There is a wide variety of E.R kits in the market for educational purposes. However, it is considered that not all kits can give the same space for collaboration skills to be developed. This research selected the E.R kit of Lego WeDo 2C because it delivers the space for construction and design phases while has the flexibility to be wirelessly connected with a computer. Another useful element that is very crucial is the opportunity to be connected with the programming language Scratch (1, 2, and 3). Scratch programming is widely used in Greek primary schools, therefore it is the logical option to be selected for the implementation of this strategic approach.

\section{Collaboration Skills}

When shifting towards the development of collaboration skills, it is very important to take into consideration that it is not an easy task. Why is it so hard? The difficulty entails within the general school system that is followed by the majority of schools and teachers. In the Greek Primary school system it is very rare for students to be engaged in conversations and negotiations in debatable issues. Most of the teaching is centered to the transmission of knowledge to the student within "foundational" type of knowledge. From one hand it is absolutely necessary for "foundational" knowledge to be built during this period of a student's life. On the other hand, certain skills do not have the time and space to be developed if there is a lack of argumentative opportunities.

We start by asking a fundamental question: Is collaboration a skill by itself or is it a set of skills that exist under the umbrella of this skill? It is not easy to answer the question. The reason behind the difficulty lays on the fact that collaboration can be sometimes seen and described by nonlinearity. For example, a student may be very collaborative within a certain group of classmates, but may not be at all collaborative within another group of classmates. Is it certain that this specific student will be collaborative if he develops these specific collaboration skills? It is not certain, but the students will have a set of very high quality skills that will make collaboration more possible. In addition, it is important for a framework of skills to be teachable, measurable and specific with indicators from low to high. A detailed set of collaboration skills is provided in Hesse et al. [1]. As the authors state, "...social skills constitute the "collaborative" part of collaborative problem solving. They play an important role in collaborative problem solving, but are also a feature of many other collaborative tasks". This means that these collaboration skills are evident in design, construction and even programming a robotic artifact. 


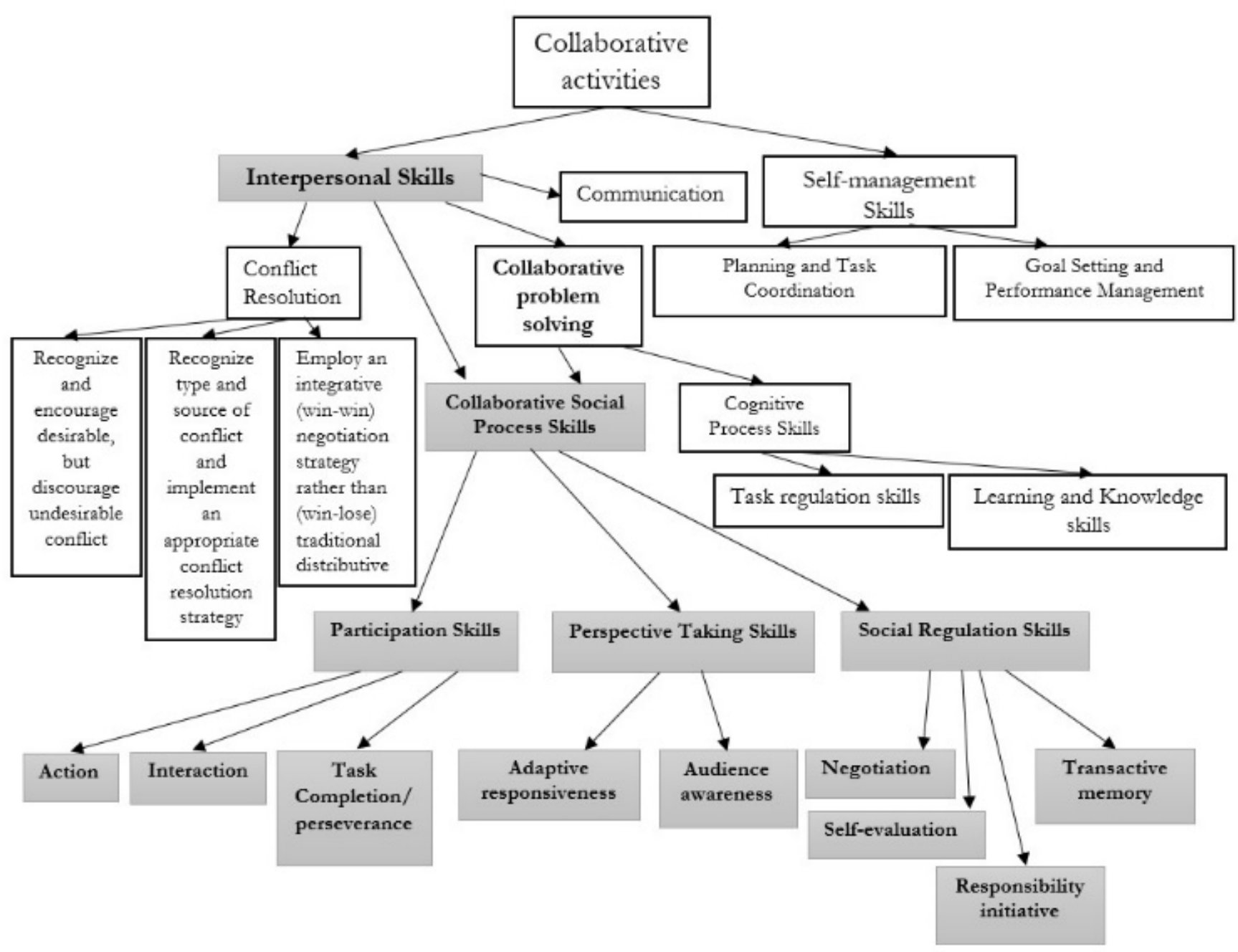

Fig. 1. The tree of skills within collaboration

However, collaborative activities are not comprised only by interpersonal skills, but according to Stevens and Campion (1994) there is another branch of skills that are evident. Eventhough self-management skills are not a part of this research, it is useful to present the full extent of these skills in Figure 1. The figure displays the set of skills that Stevens and Campion [8] created together with the new addition of Hesse et al. [1]

As shown in figure 1, there are many skills that are needed for collaboration and teamwork. The focus of this research is to cultivate a didactical strategy to develop the part of collaborative social process skills. In the effort for this, educational robotics can assist as a tool in the direction of developing such skills. The reason behind the selection of the specific skills entails within their necessity. The social process skills deliver the groundwork for the other skills to develop and play a very important role in supporting all the branches of skills. The section below presents the analysis of skills and explanations on how to measure them based on the work of Hesse and his colleagues [1] with an attempt to relate them to the educational robotics activities and settings.

The three main branches that comprise the collaboration skills are the: Participation skills, Perspective taking skills and Social regulation skills.

Participation skills: These skills can be measured by the elements of action, interaction and task completion. Action is defined by the level of participation of the individual and does not take into account if the action is coordinated with any other member of the group. When observing this particular element through the use of educational robotics, it is important to notice the number of actions of each student within the group. This action can be an uncoordinated effort to assemble some pieces of Lego bricks together with or without the presence of previous scaffolding. Action can be present in all the phases of designing, constructing, connecting, programming and testing the robotic artifact. Interaction on the other hand is defined as the behavior where a student interacts and responds to other members of the group. Interaction is a very important element in all the phases of creating a robotic artifact. Some students tend to linger within their own actions without being able to interact or coordinate their efforts with other group members. When interaction is evident between and among students it becomes understandable when a student answers questions or coordinates his/her efforts with the rest of the group members. According to Hesse et al. [1] "interaction is a minimum requirement for successful coordination and it is achieved through the verbal and non-verbal means". The task completion skills are very important when it comes to educational robotics. The importance entails on the very nature of ER because the completion of an ER project includes the progression of creation phases. For example a robotic artifact cannot be programmed if it's not properly 
connected or it cannot be working properly if the sensors are not at the right place and so on. This particular skill can differ a lot from student to student. This skill is evident when a student presents perseverance towards a task and it is expressed through engagement and commitment to reaching the completion of a task.

Perspective taking: This can be measured by the elements of adaptive responsiveness and audience awareness. An important factor in participation is the measurement of the quantity of collaborative evidence. Moving forward to perspective taking, there is more focus on the quality of interacting. So, even if there is evidence of action, interaction and task completion, there is no real evidence that a student is adaptive in his/her response towards the ideas and contributions of the other group members. In practical terms this means that even-though a response is present, it may be lacking in the adaptation that is needed. For example if there are four students in a group, trying to assemble an artifact, there may be one student or more that acts without incorporating or adapting his/her ideas to others. In a way there is more of an egocentric approach and an expectation that the others will be very similar to his/her own contributions. Adaptive responsiveness as an aspect of perspective taking can be characterized as receptive (willing to accept, adapt, incorporate and use new suggestions and ideas). Audience awareness skills on the other hand is understandable when a student is responsive to a group member's action in an expressive way. This skill can be visible to an observer when two students for example try to create the gearing system of a robotic artifact. It can be observed while student number 1 places the main gear and student number 2 responds and adds to the gear the band. Then student number 1 again responds and adds the axle for the wheel and so on. In this way the students not only act, or just respond, but respond in a coordinated, reflective and in tailored manner to the externalization of knowledge of their group members. This particular skill has as well indicators ranging from low to high.

Social regulation: This can be measured by the elements of negotiation, self-evaluation, transactive memory, responsibility initiative. These elements play a very important role in group projects and are crucial for students to have as a set of skills for the future work environment. More specifically self-evaluation describes the level of understanding a student has about his own performance in terms of strengths and weaknesses. On the other hand "transactive memory" refers to the skill a student has about understanding the performance of others within the groups. Both skills above can be evident to educational robotics projects since there are many different tasks to be addressed and groups members have to make use of the strengths each member possesses accordingly. Another very important element is the skill of negotiation. In groups that are very diverse in terms of heterogeneity the development of negotiation skills are vital for any group project, especially when it comes to projects that are ill defined with open ended answers. Negotiation skills are the skills that will permit the members of the group to reach resolutions to possible conflicts regarding many aspects of a project. Many conflicts can appear during the creation of a robotic artifact, as to what shape, size or functionalities it may have. Conflicts can also occur when strategies need to be implemented in order to tackle certain problems or decisions regarding the phases of any project. Concluding the presentation of social skills within collaborative tasks there is another important skill to be nurtured. This skill is called "responsibility initiative" and it's not present very often in group projects from students in primary schools. It is evident when students assume high responsibility and contribute to the collective efforts of the group. This particular skill is visible when students work collectively during the tasks and talk instinctually in first plural regarding the group tasks. For example if the teacher approaches the group and starts to have a conversation with the students the students respond in the manner "...we designed this automobile..." or "...we did not add the extra wheel, because we did not want to add more weight...".

The above set of collaboration skills are not developed simultaneously by all students and there is a high complexity within the terms. However, this is not a discouraging factor because the importance of using this framework entails within their specific and measurable description. It is necessary when measuring and teaching collaboration skills, not to search for vague and chaotic meanings that most of the time overlap with each-other. Testing should be based on a system of indicators and a standardized evaluation methodology for clearly measured and defined benefits [7]. This framework even though its obvious complexity delivers a sound, compact and strictly defined terminology.

Regarding educational robotics, this framework may identify the level of collaboration skills that come into action, in different phases of the creation of the robotic artifact. For example there may be no visible negotiations while students are at the initial phase of identifying the tasks, while at the redesign of a concept may occur very high levels of negotiations. One of the biggest benefits of using ER under the current educational framework, is that many phases include debatable issues that students are expected to find solid ground to develop collaboration skills. 
TABLE I: COLLABORATION SKILLS

\begin{tabular}{|c|c|c|c|c|}
\hline Element & Indicator & Low & Middle & High \\
\hline \multicolumn{5}{|l|}{ Participation } \\
\hline Action & $\begin{array}{l}\text { Activity within } \\
\text { environment }\end{array}$ & $\begin{array}{c}\text { No or very little } \\
\text { activity }\end{array}$ & $\begin{array}{l}\text { Activity in familiar } \\
\text { contexts }\end{array}$ & $\begin{array}{c}\text { Activity in familiar } \\
\text { and unfamiliar } \\
\text { contexts }\end{array}$ \\
\hline Interaction & $\begin{array}{l}\text { Interacting with, } \\
\text { prompting and } \\
\text { responding to the } \\
\text { contributions of } \\
\text { others }\end{array}$ & $\begin{array}{c}\text { Acknowledges } \\
\text { communication } \\
\text { directly or indirectly }\end{array}$ & $\begin{array}{l}\text { Responds to cues in } \\
\text { communication }\end{array}$ & $\begin{array}{c}\text { Initiates or } \\
\text { promotes interaction } \\
\text { or activity }\end{array}$ \\
\hline $\begin{array}{l}\text { Task completion/ } \\
\text { perseverance }\end{array}$ & $\begin{array}{l}\text { Undertaking and } \\
\text { completing a task or } \\
\text { part of a task } \\
\text { individually }\end{array}$ & $\begin{array}{l}\text { Maintains presence } \\
\text { only }\end{array}$ & $\begin{array}{l}\text { Identifies and } \\
\text { attempts the task }\end{array}$ & $\begin{array}{l}\text { Perseveres in task as } \\
\text { indicated by } \\
\text { repeated attempts or } \\
\text { multiple strategies }\end{array}$ \\
\hline \multicolumn{5}{|l|}{ Perspective taking } \\
\hline $\begin{array}{l}\text { Adaptive } \\
\text { responsiveness }\end{array}$ & $\begin{array}{l}\text { Ignoring, accepting } \\
\text { or adapting } \\
\text { contributions of } \\
\text { others }\end{array}$ & $\begin{array}{l}\text { Contributions or } \\
\text { prompts from others } \\
\text { are taken into account }\end{array}$ & $\begin{array}{l}\text { Contributions or } \\
\text { prompts of others are } \\
\text { adapted and } \\
\text { incorporated }\end{array}$ & $\begin{array}{c}\text { Contributions or } \\
\text { prompts of others } \\
\text { are used to suggest } \\
\text { possible solution } \\
\text { paths } \\
\end{array}$ \\
\hline $\begin{array}{c}\text { Audience awareness } \\
\text { (Mutual modelling) }\end{array}$ & $\begin{array}{l}\text { Awareness of how to } \\
\text { adapt behavior to } \\
\text { increase suitability } \\
\text { for others }\end{array}$ & $\begin{array}{c}\text { Contributions are not } \\
\text { tailored to } \\
\text { participants }\end{array}$ & $\begin{array}{l}\text { Contributions are } \\
\text { modified for recipient } \\
\text { understanding in the } \\
\text { light of deliberate } \\
\text { feedback }\end{array}$ & $\begin{array}{l}\text { Contributions are } \\
\text { tailored to recipients } \\
\text { based on } \\
\text { interpretation of } \\
\text { recipients' } \\
\text { understanding } \\
\end{array}$ \\
\hline \multicolumn{5}{|l|}{ Social regulation } \\
\hline Negotiation & $\begin{array}{c}\text { Achieving a } \\
\text { resolution or reaching } \\
\text { compromise }\end{array}$ & $\begin{array}{l}\text { Comments on } \\
\text { differences }\end{array}$ & $\begin{array}{c}\text { Attempts to reach a } \\
\text { common } \\
\text { understanding }\end{array}$ & $\begin{array}{l}\text { Achieves resolution } \\
\text { of differences }\end{array}$ \\
\hline $\begin{array}{l}\text { Self-evaluation } \\
\text { (Metamemory) }\end{array}$ & $\begin{array}{c}\text { Recognizing own } \\
\text { strengths and } \\
\text { weaknesses }\end{array}$ & $\begin{array}{l}\text { Notes own } \\
\text { performance }\end{array}$ & $\begin{array}{c}\text { Comments on own } \\
\text { performance in terms } \\
\text { of appropriateness or } \\
\text { adequacy }\end{array}$ & $\begin{array}{c}\text { Infers a level of } \\
\text { capability based on } \\
\text { own performance }\end{array}$ \\
\hline Transactive memory & $\begin{array}{c}\text { Recognizing } \\
\text { strengths and } \\
\text { weaknesses of others }\end{array}$ & $\begin{array}{c}\text { Notes performance of } \\
\text { others }\end{array}$ & $\begin{array}{c}\text { Comments on } \\
\text { performance of others } \\
\text { in terms of } \\
\text { appropriateness or } \\
\text { adequacy }\end{array}$ & $\begin{array}{c}\text { Comments on } \\
\text { expertise available } \\
\text { based on } \\
\text { performance history }\end{array}$ \\
\hline $\begin{array}{l}\text { Responsibility } \\
\text { initiative }\end{array}$ & $\begin{array}{l}\text { Assuming } \\
\text { responsibility for } \\
\text { ensuring parts of task } \\
\text { are completed by the } \\
\text { group }\end{array}$ & $\begin{array}{l}\text { Undertakes activities } \\
\text { largely independently } \\
\text { of others }\end{array}$ & $\begin{array}{l}\text { Completes activities } \\
\text { and reports to others }\end{array}$ & $\begin{array}{l}\text { Assumes group } \\
\text { responsibility as } \\
\text { indicated by use of } \\
\text { first person plural }\end{array}$ \\
\hline
\end{tabular}

Source: In P. Griffin, \& E. Care (Eds.) (2015). Assessment and Teaching of 21st Century Skills (pp. New York: Springer. - Chapter 2 “A Framework for teachable Collaborative Problem Solving Skills. Friedrich Hesse, Esther Care, Juergen Buder, Kai Sassenberg and Patrick Griffin.

\section{The STRATEGY}

It is necessary when developing a strategy for implementing a framework for the creation of collaboration skills using educational robotics not to transform a joyful and meaningful experience into a boring "business as usual" type of didactical process. Why is it necessary? Because the students at the age of 11 have a playful view of Lego kits. This playful view of Lego kits enhance in great extent their engagement towards the robotics activities and must be harnessed in a constructive and resourceful way.

The concept behind the proposed framework even though it may seem simple in a first glance, it is quite difficult for students to grasp immediately and there is a need of a period in which the students and the teacher should be engaged in deeper conversations in order to ensure mutual understanding. Shifting from a totally teacher centric system into a system that students are empowered to make their own rules, decide for themselves, negotiate ideas, resolve conflicts and finally converge and create shared meanings is a demanding process. It is the process that Bruffee [9] called reacculturation and it is the fundamental cornerstone of this framework.

Even though the framework aims to empower students, it is inevitable for some social engineering to take place. The reason behind social engineering lays on a multiple of reasons. Firstly, the students are quite immature in creating 


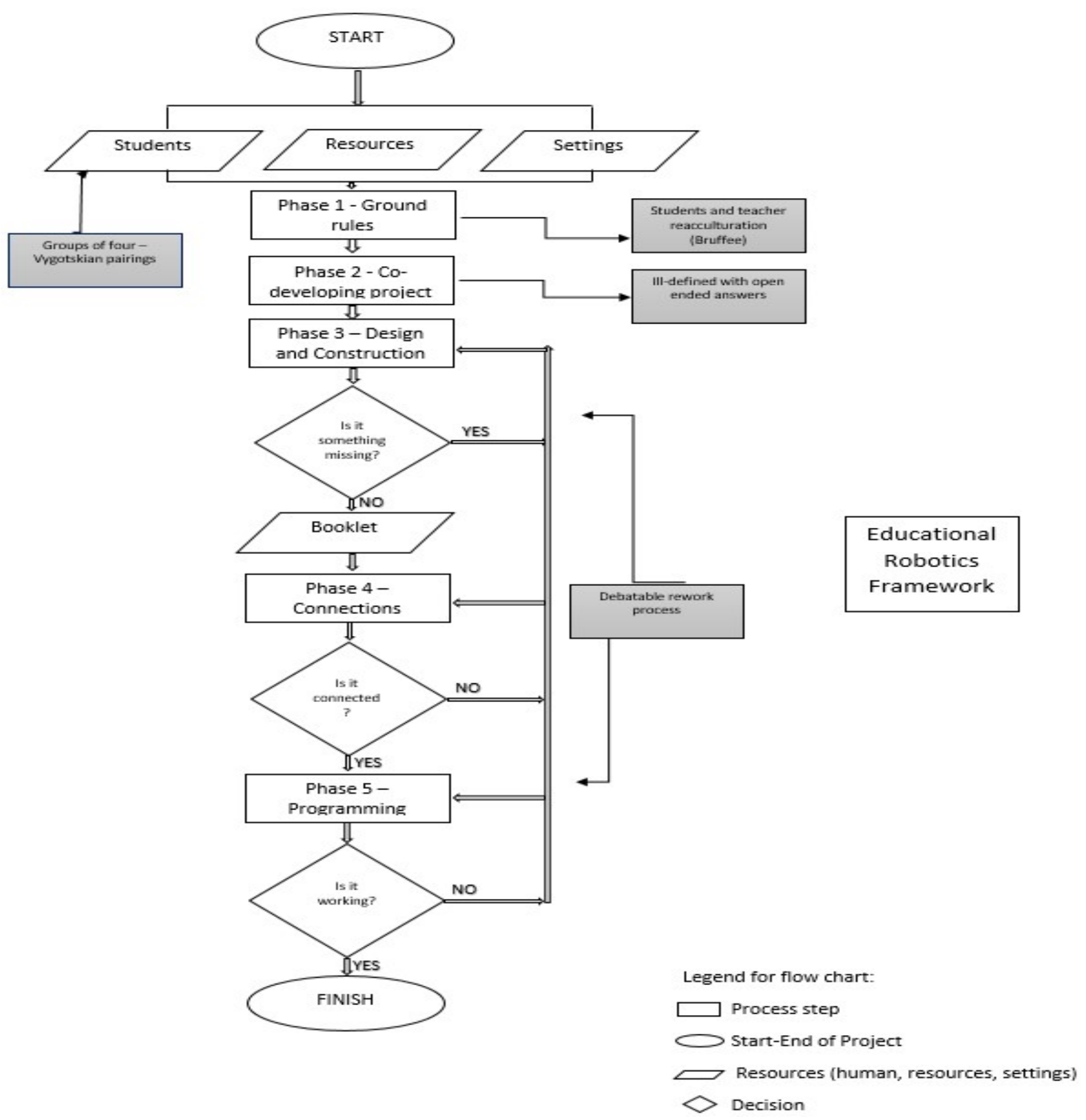

Fig. 2. The Framework for the development of Collaboration Skills using Educational Robotics

heterogeneous groups by themselves and most of the time group with their friends. Another very important reason is that being classmates for 5 years (being in the $6^{\text {th }}$ grade) there are interpersonal problems that exist between and among some students. It is important for the teacher to identify these problems quite early in the process and separate the bases of tension. But, the most important issue that has to be considered are the social skills that students already have or do not have. So, it is useful to create pairings within the groups that follow the Vygotskian [10] pattern. This means grouping one student with social skills together with a student that does not have (or possess less) social skills. Another element that has been noticed is, that it is useful for gender balance to exist within the groupings of four (whenever it's possible).
The number of the members of the groups is a very crucial element that needs to be taken very seriously. Groups of four members have been chosen to be the appropriate size. During the last years when implementing educational robotics projects, it has been observed that during one didactical hour there were fewer interactions between students when the groups had more than five members. Often some of the more quiet kids were left behind and this created a heavier need for the teacher to intervene continuously in order to keep the balances. This was often hard and it was gradually becoming very difficult to manage when for example there were deadlines to meet (national competitions often have strict deadlines). When the groupings were made with five members, there was a unique advantage when it came to speed of decision making and generally there was a larger pool of ideas, however these ideas did not often have the time 
to be addressed in meaningful conversations. On the other hand, when there were three members in groups there was lack in adequate diversity among the members'. If there is an option, however, to choose a group of three or a group of five if the class size cannot offer perfect groupings of four then the decision should incline more to the smaller size of the group if the main purpose of the project is to develop high level collaboration skills. For this empirical study that is presented later (that happened last year), the class was divided in four perfect groupings of four students. However, the new class that is currently (since September 14, 2020) being researched did not offer perfect groupings of four (class of 22 students) so the groupings included two groups of three members.

TABLE II: FRAMEWORK SETTINGS

\begin{tabular}{ll}
\hline \hline & \multicolumn{1}{c}{ Settings } \\
\hline Working space & Two couple per workbench \\
Group size & Vygotskian pairings (four students) \\
Time & 1h/week/school year \\
E.R Kit & Lego WeDo 2 \\
Gender & Mixed groups \\
Age & 11-12 years old \\
E.R Project & Agreed by all - ill-defined with open ended \\
Teacher stance & answers \\
Prior knowledge & Collaborator - mediator \\
Connections & Booklet with detailed instructions \\
Curriculum & Part of Computer Science \\
\hline \hline
\end{tabular}

A very important element that can create more debatable conversations and indirectly lay the ground for meaningful arguments is the type of the project that the students will be engaged with. Will it be a project with open ended answers or a single answer? Will it be well defined or ill-defined? It may seem easy to pick the open ended answer project because the literature on the topic urges us to, but how open? How much ill defined? Those are crucial questions that the teacher has to be prepared to face and make useful suggestions to the students. In this case the students expressed many ideas like automatic umbrellas, flying objects, ships and cars with automatic properties that either exist in the real world or not. After a conversation that took two didactical hours the result was that the students chose to create an automatic vehicle that when reaches a cliff (the edge of a white table) to stop moving before falling off. It could be characterized as ill-defined since the vehicle can move in various ways, can use different type of sensors, be programmed to be timed or react when reaching the edge of the table, the start point can be wherever within the table and so on. In addition it provides the openended answer requirement, in order for debatable conversations to take place.

What will be the relation between the groups? Will it be cooperative or competitive? It is a question that has to be answered by the students. The students in our case chose to be cooperative and not competitive. The element of being cooperative is important because the extension of being cooperative outside of the group gives an even larger space for the collaboration skills to be developed. Having mentioned this, it is useful to add that even students had the opportunity to use this option, they rarely used and preferred to activate this privilege.

\section{THE EMPIRICAL STUDY}

This pilot phase of implementing the framework for the development of collaboration skills was conducted during thirteen one-hour sessions that took place within the school's computer science laboratory. During these thirteen hours the developed and enhanced their collaboration skills. It is important to mention at this point that this exploratory empirical study came to an end due to the coronavirus lockdown of the schools. However, these thirteen hours laid a solid ground for the continuation of the research work since September $14^{\text {th }} 2020$. At this stage, it is important to state that the students engaged in the class did not have any prior experience with educational robotics or the robotic kit of Lego WeDo 2.

\section{A. Phase one}

At this initial phase the students were asked to form the ground rules for their engagement with the educational robotics project. If the students did not all agree in a certain rule, the rule would be discarded. This was the first exercise for the students to attempt creating common understandings and the first form of convergence. This phase was concluded in two sessions of one hour per session. During these two sessions the students had the opportunity to express their opinion about many issues that were worried about. The elements that the students were mostly concerned are as follows:

- Badmouthing

- Exclusion of student from the group

- Egoism and selfishness

- Student loafing

- Conflicts that go back in time

- Fear to face the challenge of robotics

- Punishment

Most of the issues were somewhat expected, but punishment was an issue that had the teacher very concerned. When the teacher asked the students for more details, the students responded that the groups should be able to expel or punish otherwise the students that do not lift their own weight towards the project. This hindered a feeling from many students there were unresolved problems between them. The teacher in the effort to address the concerns of the students, responded that the robotic activities that the students are about to be engaged with, have difficulties and some students may find it hard at the beginning, so it is wise for all to be very patient with each other because all people have different pace when faced with new challenges. This comment from the teacher made the students reconsider their stance towards the punishment element. The following rules were agreed among the students and the teacher in order for the problems above to be treated accordingly:

i. All the members of the teams are equal

ii. When a member of your team is talking, do not talk and think what they are saying

iii. If you think what they say, tell them what it is that you like

iv. If you didn't have the time to think, take your time to think and when you are ready express your opinion or if you didn't understand something ask a question

v. It is good when you are talking to look at eachother in the eyes

vi. Do not talk in a bad manner or in an 
underestimating way to no one, however much you disagree. Remember that many great ideas are created when people disagree with each-other in a civilized and kind way.

vii. Make many questions! You will see that you have all the answers within you (all of you).

viii. Some students are very talkative and some are less talkative and some do not talk at all. Remind your classmates that talk a lot to talk less and help the students that don't talk much to step in the conversation. If a student is still not talkative respect this fact and let them step in the conversation when they feel ready to do so. In this way more students will participate and will be fairer for all.

ix. When something doesn't go the way it is supposed to be, take a small break and reflect back to what you have achieved as a team and do not stress. If you need assistance ask the teacher for help.

x. And remember...all for one and one for all!

This first exercise of convergence was very meaningful in order for students to understand that their thoughts and opinions are not only taken into consideration but form the realities around them and within their own group.

\section{B. Phase two}

The next step was for the students and the teacher to reach an agreement of the educational robotic project. This phase lasted for two one-hour sessions. During this time the students came up with many interesting ideas. It is important at this point to state that the teacher acted as a mediator and a facilitator. When mediating the teacher aimed to include as many students as possible within the conversation and the negotiations. When facilitating the teacher aimed to make things easier while the students were brainstorming for ideas. So for example, if an idea did not include the necessary sensors or included other parts that were not in the robotic kit, the teacher would ask questions on how to replace the functionality with something else, or enhance the ideas with the appropriate automatisms. It was essential for students at this stage to converge through negotiations into a final project statement that is was accepted by all. The final statement was to "create any type of vehicle that stops automatically when reaching a cliff", the cliff was considered to be the edge of the table. Al students were excited to enter within the project and started working. The project statement reflected perfectly the notion of ill-defined with open-ended answers.

\section{Phase three}

When the students were given the robotic kits, were very excited to explore and investigate the bits and pieces. There were many attempts to create the first constructions. The students at this phase were highly active but there was no real interaction between them. The element of perseverance was high. The teacher at this stage did not intervene, but was actively observing the whole work process in the class.

This third phase could be divided in terms of collaboration skills in three sub-phases. It is very interesting to mention that the progress of the robotic kits was following the progress of the collaboration skills that the students were either activating or developing. More specifically during the first sub-phase that lasted for approximately two hours the students were mainly concerned of the understanding of the bits and pieces and only by the end of the second hour started asking questions to each other like "what do you think this piece does?"

The sub phase 2 (2-3 hours) was different than the first two hours. During this sub-phase there were conversations and slowly but gradually all the groups presented verbal and nonverbal interactions ranging from low to medium.

During sub-phase 2 group 1 was negotiating in terms of design. One student was creating a small construction and was presenting it to the other group members, while the others expressed their disagreement or agreement by deconstructing or adding pieces to the artifact. The non-verbal interactions became slowly and gradually verbal. Group 1 by the end of these two hours had managed to create an artifact without gears, sensors or a motor. The artifact looked like a vehicle with four wheels.

Group 2 at this stage had three members (one was absent for many days from school) and were anxious overlooking the progress of the rest of the groups. The teacher approached the group and tried to investigate if there are any issues to be addressed. Two of the students expressed their complaints that the third member did not contribute in a satisfactory level. The third member on the other hand accused the other two that did not include him in the process. The teacher repeated the ground rules that the students created and agreed upon and sat beside the group's table to ensure that the climate between the students was back to a functional state. One of the students expressed the will to ask questions to other groups or group members. The teacher responded that this should be agreed with the whole class. The class responded positively and some verbal interaction was present between the members of group 1 and group 2. The members of group2 felt relieved and continued their efforts in a more collaborative manner without applying pressure to each other. Group 2 managed to construct a vehicle that resembled a motorcycle without gears, motors or the hub unit.

Group 3 was highly engaged with the construction of the artifact. Member 1 expressed high support to member 2 in order to invite the girl in the collaborative process. This group did interact but many contributions of the members were not tailored to each other views and ideas. By the end of this subphase produced two different artifacts that both did not have gears, motor or sensors. One artifact was the construction of the member that was within the spectrum of autism and the other artifact was the creation of the rest of the group members. When the teacher approached group 3 the members tried to explain that the second artifact was a type of wagon that should be connected to the main vehicle.

Group 4 had many problems with their internal dynamics and mainly member 3 continuously wanted to push her ideas and contributions towards the other members. The result was that the rest of the members did not fully participate. This group had two members that had the highest marks in class during the last years. The other member of this group that had the highest marks was a boy and during the process of the group preferred to remain passive and his level of participation was low. When this was noticed the teacher had 
a conversation with the group in order to remind them the ground rules and analyze some basic facts about collaboration and teamwork. The aim was to focus mainly on the elements of perspective taking and social regulation. Group 4 eventually did manage to construct an artifact that resembled a truck without gears or sensors. This happened after the teacher sat for approximately 30 minutes to mediate the procedure.

Proceeding to sub-phase 3 (2-3 hours) group 1 and group 2 had many conversations within their own groups about the usage of the parts with cables. Both groups found how to connect the sensors and the motors with the hub unit and wondered actively how their discovery can be integrated into their artifacts. One member of group 3 asked a member of group 2 the details of connecting the sensors and the hub unit and then group 3 proceeded with the connections. Group 4 slowly stepped into this sub-phase and started having investigative conversations as well.

Al the groups eventually redesigned many times their robotic artifacts into a state that it was visible that all the questions that had to be addressed were expressed through the constructions.

\section{Phase four}

It should be noted that this phase and the next did not have the opportunity to be introduced due to the schools lockdown policy. However, it would be interesting to mention that the connection phase is not an easy one. The difficulty entails within the use of Scratch programming. In order for the students to connect the hub with the Scratch program, there is a connecting program called s2Bot that has to be activated first. This procedure is very demanding, so the decision was to fully illustrate the procedure in a handout and let the students coordinate their efforts to connect the robotic artifact.

During this phase the students should be expected to practice some of the collaboration skills that developed during the previous phase. An option that was considered by the teacher was to introduce the Jigsaw technique. The Jigsaw technique can be useful in standardizing the pieces of information that are "foundational". But would the Jigsaw technique be compatible? It must be reminded that until this phase the students created equally the knowledge that permitted them to construct their robotic artifact. How would the dynamics within the groups change if there is injection of knowledge on some members of the groups? Would it create a form of hierarchy? The answer is unclear.

The other thought is to create another decision making process where the students will be asked to manage the given "foundational" knowledge. Would they decide to divide the workload in a cooperative manner (not collaborative) or would they decide to continue their deeper collaboration pattern.

Whether the students use the Jigsaw technique or something else it is thought to be the subject of discussion among students and the teacher. Based on the observations, students at this particular experiment should, without major difficulties, be able to complete the connections with or without the use of Jigsaw technique.

\section{E. Phase five}

As mentioned earlier, students at the $6^{\text {th }}$ grade of elementary school have a wide variety of computer skills and knowledge. The Scratch programming language is very popular among students in Greece and most of the students know how to use sequence, repetition and selection. This knowledge comes very handy, during this last phase. In relation to collaboration skills, students will be expected create simple strategies, converge their knowledge into solving programming problems and make the necessary modifications and rework when it is needed. Again, this phase gives even more time and space for debatable conversations in order to further develop the students' collaboration skills.

\section{Collaboration Skills ObServations}

Before concluding it is essential to present the observations that have been made in relation to collaboration skills.

Students without any exceptions were highly active and presented activity in familiar and unfamiliar contexts. Unfamiliar context is perceived as the phase that consisted of the usage of the educational robotics kits. On the other hand interaction was visible by all students during the two initial phases, but was not visible during the start of phase 3 were students were mainly focused in understanding the bits and pieces individually for some time. However, this changed, as the students started creating small artifacts. Slowly, nonverbal interactions were becoming verbal and by the end of phase 3 all students increased their level of interaction. It is important to state that the student within the spectrum of autism achieved to respond to cues in communication. Perseverance was at the highest point and the students attempted repeated attempts and multiple strategies.

The students of group 1 and group 2 presented gradual improvement in accepting and adapting the contributions of others during phase 3 and more specifically during subphases 2 and 3. Students of group 3 tried hard to incorporate the contributions of the student within the spectrum of autism, while trying to contribute their own efforts in an adaptive manner. Students of group 4 had many problems at perspective taking but managed eventually with the help of the teacher to start accepting and then adapting their individual contributions.

All students engaged in negotiations while constructing the artifacts. Some students negotiated more and some less, however, all group members achieved to reach compromises that led to successful creation of a robotic artifact. If the compromise was the result of one's submission or a successful resolution, it needs more information that this research in this exploratory pilot phase did not gather. All students reaching the end of the construction assumed responsibility for the tasks and referred to the tasks by the use of first person plural. Even though the students of group 2 did express some comments on their own performance recognizing some weaknesses, there were no other observations of comments from other students expressing comments on performance of other or of their own. 


\begin{tabular}{|c|c|c|c|c|c|c|c|c|c|c|c|c|c|c|c|c|c|c|c|c|c|c|c|c|c|c|c|}
\hline & \multicolumn{27}{|c|}{ Construction Phase of robotic artifact } \\
\hline & \multicolumn{9}{|c|}{ Participation } & \multicolumn{6}{|c|}{ Perspective Taking } & \multicolumn{12}{|c|}{ Social Regulation } \\
\hline & \multicolumn{3}{|c|}{ Action } & \multicolumn{3}{|c|}{ Interaction } & \multicolumn{3}{|c|}{ Perseverance } & \multicolumn{3}{|c|}{ Ad. Responsive } & \multicolumn{3}{|c|}{ Aud.Awareness } & \multicolumn{3}{|c|}{ Negotiation } & \multicolumn{3}{|c|}{ Self-evaluation } & \multicolumn{3}{|c|}{ Trans. Memory } & \multicolumn{3}{|c|}{ Resp.Initiative } \\
\hline & $\mathrm{L}$ & $\mathrm{M}$ & $\mathrm{H}$ & $\mathrm{L}$ & $\mathrm{M}$ & $\mathrm{H}$ & $\mathrm{L}$ & $\mathrm{M}$ & $\mathrm{H}$ & $\mathrm{L}$ & $\mathrm{M}$ & $\mathrm{H}$ & $\mathrm{L}$ & $\mathrm{M}$ & $\mathrm{H}$ & $\overline{\mathrm{L}}$ & $\mathrm{M}$ & $\mathrm{H}$ & $\mathrm{L}$ & $\mathrm{M}$ & $\mathrm{H}$ & $\mathrm{L}$ & $\mathrm{M}$ & $\mathrm{H}$ & $\mathrm{L}$ & $\mathrm{M}$ & $\mathrm{H}$ \\
\hline Student1 & & & & & & & & & & & & & & & & & & & & & & & & & & & \\
\hline Student2 & & & & & & & & & & & & & & & & & & & & & & & & & & & \\
\hline Studentn & & & & & & & & & & & & & & & & & & & & & & & & & & & \\
\hline Add. & $\Sigma$ & $\Sigma$ & $\bar{\Sigma}$ & $\Sigma$ & $\Sigma$ & $\Sigma$ & $\Sigma$ & $\Sigma$ & $\Sigma$ & $\Sigma$ & $\Sigma$ & $\Sigma$ & $\bar{\Sigma}$ & $\Sigma$ & $\Sigma$ & $\Sigma$ & $\bar{\Sigma}$ & $\Sigma$ & $\Sigma$ & $\Sigma$ & $\Sigma$ & $\Sigma$ & $\Sigma$ & $\bar{\Sigma}$ & $\bar{\Sigma}$ & $\bar{\Sigma}$ & $\Sigma$ \\
\hline Perc.\% & $\%$ & $\%$ & $\%$ & $\%$ & $\%$ & $\%$ & $\%$ & $\%$ & $\%$ & $\%$ & $\%$ & $\%$ & $\%$ & $\%$ & $\%$ & $\%$ & $\%$ & $\%$ & $\%$ & $\%$ & $\%$ & $\%$ & $\%$ & $\%$ & $\%$ & $\%$ & $\%$ \\
\hline
\end{tabular}

TABLE II: FRAMEWORK SETTINGS

\section{WhAT IS NEXT?}

The first author recognizes the weakness of this first exploratory research attempt in terms of gathering information. Because of this it is considered that the following years, this research should be enhanced with agents (human, audio or video recording devices). The agents will shed light to more information regarding some fine elements that are impossible to be measured solely through observation.

In addition to the use of agents, there will be introduction of the table that will standardize the measurements with a higher degree of preciseness. The table has the theoretical bases of what Hesse [1] and his colleagues proposed. The table will be used frequently within the processes of this educational robotics framework in order to locate the changes in students' skills depending on the tasks and procedures they work on. This will also hopefully shed more light to the connection between robotic tasks and procedures to the creation of collaboration skills.

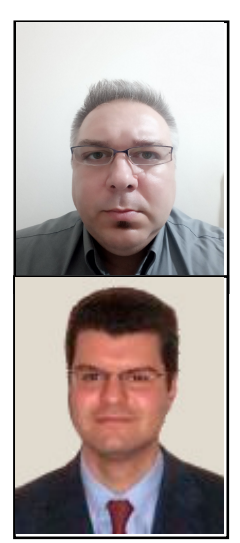

Emmanouil A. Demetroulis was born on 1977 in New York, U.S.A. He studied in Coventry University U.K at the Department of Electrical and Electronic Engineering. He holds a B.Eng and M.Sc in Engineering and Engineering Business Management. $\mathrm{He}$ is currently a Ph. D student at the University of Peloponnese.

Nikos Platis Since February 2017 he has been an Assistant Professor at the Department of Informatics and Telecommunications of the University of Peloponnese in Graphics and Visualization. He received a degree in Mathematics from the University of Athens in 1995, a postgraduate degree in Informatics from UCL in London in 1996 and a PhD in Informatics in the field of Graphics from the Department of Informatics and Telecommunications of the University of Athens in 2005.

\section{REFERENCES}

[1] F. Hesse, E. Care, J. Buder, K. Sassenberg and P. Griffin "A Framework for teachable Collaborative Problem Solving Skills" in Assessment and Teaching of $21^{\text {st }}$ Century Skills, P. Griffin, E. Care, Educational Assessment in an Information Age New York: Springer, Dordrecht IEEE Press, 2015, pp. 37-56.

[2] J. Roschelle, "Learning by collaborating: Convergent conceptual change. Journal of the Learning Sciences 2, pp. 235-276, 1992

[3] J. Roschelle \& S. D., Teasley "The construction of shared knowledge in collaborative problem-solving. In, C.E O'Maley (Ed), ComputerSupported collaborative learning, Berlin: Springer-Verlag, 1995, pp. 69-97.

[4] T. Panitz (1992). "Collaborative versus cooperative learning: A comparison of the two concepts which will help us understand the underlying nature of interactive learning" [Online]. Available: http://home.capecod.net/ tpanitz/tedsarticles/coopdefinition.htm

[5] P. Dillenbourg "What do you mean by "collaborative learning?"” In P. Dillenbourg, Collaborative-Learning: Cognitive and Computational Approaches. Oxford: Elsevier pp. 1-19, 1999.

[6] A. Eguchi, "What is educational robotics? Theories behind it and practical implementation" in Proc. Of Society for Information Technology \& Teacher Education International Conference. 2010, pp. 4006-4014.

[7] D. Alimisis, "Open questions and new challenges," In Themes in Science \& Technology Education Dallas, 6(1), 2013.

[8] J. M. Stevens \& A.M. Campion "The Knowledge, Skill, and Ability Requirements for Teamwork: Implications for Human Resource Management" Journal of Management, (1994). Vol. 20, No. 2, 503-530.

[9] K. A. Bruffee "Collaboration, conversation and reacculturation," in K. A. Bruffee Collaborative Learning: Higher Education, Interdependence and the Authority of Knowledge, MD: John Hopkins University Press, 1993.

[10] L. S. Vygotsky, Mind in Society: The Development of Higher Psychological Processes, Ed and trans., M. Cole, V. John-Steiner, S. Scribner and E. Souberman, Cambridge, MA: Harvard University Press 1978

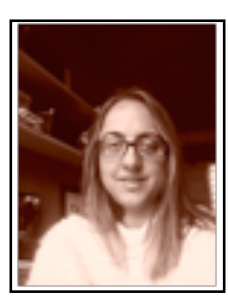

Angeliki Antoniou holds a $\mathrm{PhD}$ on Information Science from University of Peloponnese, an MSc in Human- Computer Interaction with Ergonomics from University College London and a Bachelor of Science (BSc) in Social and Clinical Psychology from the University of Kent at Canterbury. She also holds a Piano Diploma (class of Professor M. Halleker), Metropolitan Conservatory, Athens. She holds a Degree of Preschool Education, National and Kapodistrian University of Athens.

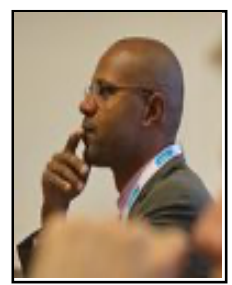

Manolis Wallace was born in Athens in 1977. In 2001 he received a diploma in electrical and computer engineering and in $2005 \mathrm{a} \mathrm{PhD}$ in intelligent knowledge-based systems in uncertain environments, both from NTUA's School of Electrical and Computer Engineering. Since 2007 he is a faculty member at the Department of Informatics and Telecommunications of the University of Peloponnese, while at the same time and up to 2013 also a senior researcher at the Foundation of the Hellenic World. 
Vassilis Poulopoulos was born in Kalamata in 1982

received his diploma from the Computer Engineer and

Informatics Department of the University of Patras in

2005. He obtained an MSc and PhD from the same

department in 2007 and 2010 accordingly in data

mining and analysis from heterogenous sources of the

web and especially big data. 